\title{
Move or die: change in European catfish (Silurus glanis L.) behaviour caused by oxygen deficiency
}

\author{
T. Daněk ${ }^{(1), \star}$, L. Kalous ${ }^{(1)}$, M. Petrtýl(1), P. Horký(1) \\ Received October 25, 2013 \\ Revised April 17, 2014 \\ Accepted April 17, 2014
}

\section{ABSTRACT}

Key-words: $\quad$ European catfish (Silurus glanis L.) is a large predatory fish native to an exinvasive species, tensive area in Europe. It has been introduced to its western and southern Silurus glanis, parts, where it is considered an invasive species with a negative impact on winter, behaviour, hypoxia native fishes. European catfish is a territorial species exhibiting site fidelity. Cold water in winter usually leads catfish to exhibit notably low activity. Nevertheless, our telemetric study on 19 juvenile individuals of S. glanis provides information on their unexpected high activity and displacement in winter. Our data reveal that these behavioural changes were caused by oxygen deficiency. Our data also indicate that oxygen deficits may induce migrations of this species.

\section{RÉSUMÉ}

Bouger ou mourir : changement de comportement du silure glane (Silurus glanis L.) causé par un manque d'oxygène

Mots-clés : espèces envahissantes, Silurus glanis, hiver, comportement, hypoxie
Le silure glane (Silurus glanis L.) est un grand poisson prédateur indigène à une vaste aire en Europe. II a été introduit dans les parties occidentales et méridionales de cette aire, où il est considéré comme une espèce envahissante ayant un impact négatif sur les poissons indigènes. Le silure glane est une espèce territoriale présentant une fidélité au site. L'eau froide en hiver entraîne généralement le silure glane à présenter notamment une faible activité. Néanmoins, notre étude télémétrique sur 19 individus juvéniles de $S$. glanis fournit des informations sur leur activité élevée inattendue et leur déplacement en hiver. Nos données révèlent que ces changements de comportement ont été causés par un manque d'oxygène. Nos données indiquent également que les déficits d'oxygène peuvent provoquer des migrations de cette espèce.

\section{INTRODUCTION}

In fish, like in other poikilothermic organisms, the metabolic rate correlates with water temperature; the activity of fish in the temperate zone therefore usually decreases in winter (Ultsch, 1989). This low physiological activity may result in higher predation by homoeothermic predators such as birds or mammals (Stewart et al., 2005; Dekar et al., 2010). However, there is a more serious threat affecting the fish stock during winter in some localities; namely, oxygen

(1) Czech University of Agriculture, Faculty of Agrobiology, Food and Natural Resources, Department of Zoology and Fisheries, 16521 Praha 6 - Suchdol, Czech Republic

* Corresponding author: tomas-danek@centrum.cz 
deficiency. This is common in shallow eutrophic lakes with prolonged ice and snow cover, which greatly reduces oxygen absorption and generation. Insufficient water inflow and accumulation of decomposing organic matter, e.g. leaf litter from trees, are also factors that contribute to reducing dissolved oxygen (hereafter DO) in the water column (Fast, 1994). The most serious manifestations of oxygen deficiency can occasionally cause fish mortality events known as winterkills (Ellis and Stefan, 1989; Danylchuk and Tonn, 2006). Changes in fish behaviour may also occur, such as changes in activity; however, these changes are difficult to detect without appropriate techniques such as telemetry (Bauer and Schlott, 2006). Protective measures are commonly taken to prevent oxygen deficiency, including snow removal, cutting holes in ice and artificial aeration (Fast, 1994). However, the evaluation of such actions in natural habitats may be complicated without parallel monitoring of DO levels and because some of these actions in some cases may only increase the local chemical consumption of oxygen (e.g. by detritus decomposition), while DO in the water column does not increase significantly (Ellis and Stefan, 1989).

The European catfish (Silurus glanis L.) is a common inhabitant of rivers, old oxbows and shallow alluvial lakes in the Eurasian temperate zone. Although S. glanis is native to mainland Europe, reaching the Rhine River in the west, it has also been introduced into a number of countries in southern and western Europe, and its possible predation and competitive impact on native species is being increasingly studied and discussed (Copp et al., 2009; Bevacqua et al., 2011; Martino et al., 2011). The European catfish exhibits site fidelity and utilises a stable 'resting place' (Carol et al., 2007). It has a physiological optimum above $25{ }^{\circ} \mathrm{C}$ (Copp et al., 2009). In the temperate zone, cold water in winter leads European catfish to exhibit notably low activity (Lelek et al., 1964; Slavík et al., 2007).

This paper presents data on a phenomenon accidentally observed during a long-term study, which was originally carried out to examine seasonal changes in the activity of European catfish. We found a conspicuous increase in the movement and relocation of European catfish in winter and tested our hypothesis that these behavioural changes were induced by oxygen deficiency. We further discuss the inefficiency of winterkill protection management at the locality. Although our data are limited and represent only one season, they provide valuable new information about catfish winter behaviour.

\section{MATERIALS AND METHODS}

\section{$>$ LOCALITY}

The study area (Figure 1) is an old disconnected oxbow lake of the river Elbe situated in Central Bohemia (Czech Republic, GPS 50 $\left.10^{\prime} 48.005^{\prime \prime} \mathrm{N}, 14^{\circ} 47^{\prime} 32.713^{\prime \prime} \mathrm{E}\right)$. This lake was formerly part of the river Elbe but has been isolated since around 1930, when the river was channelised. The lake has one small inflow and no outflow. From November to March ice and snow may occur. The extent of the ice cover is directly dependent on weather conditions. During ice cover periods, ice holes approximately $5 \times 10 \mathrm{~m}$ in size are cut by members of the local anglers' organisation. Holes are cut irregularly about twice a month. The lake represents a highly valuable natural habitat that is part of the "Hrbáčkovy tůně" natural reserve and also part of the European Ecological Network Natura 2000. The maximum depth of the lake reaches $2.3 \mathrm{~m}$. The field work was authorised by the Regional Office of the Central Bohemia Region, Department of Environment and Agriculture (permit No. 114123/2010/KUSK-3).

\section{> FISH TAGGING}

A total of 19 juvenile European catfish in the weight and size ranges of 203-285 g (standard length $340-388 \mathrm{~mm}$ ) were caught at the study site by electrofishing (650 V, 4 A, pulsed D.C.) between 7 th October and 9th October 2010. The fish were temporarily kept in cages 


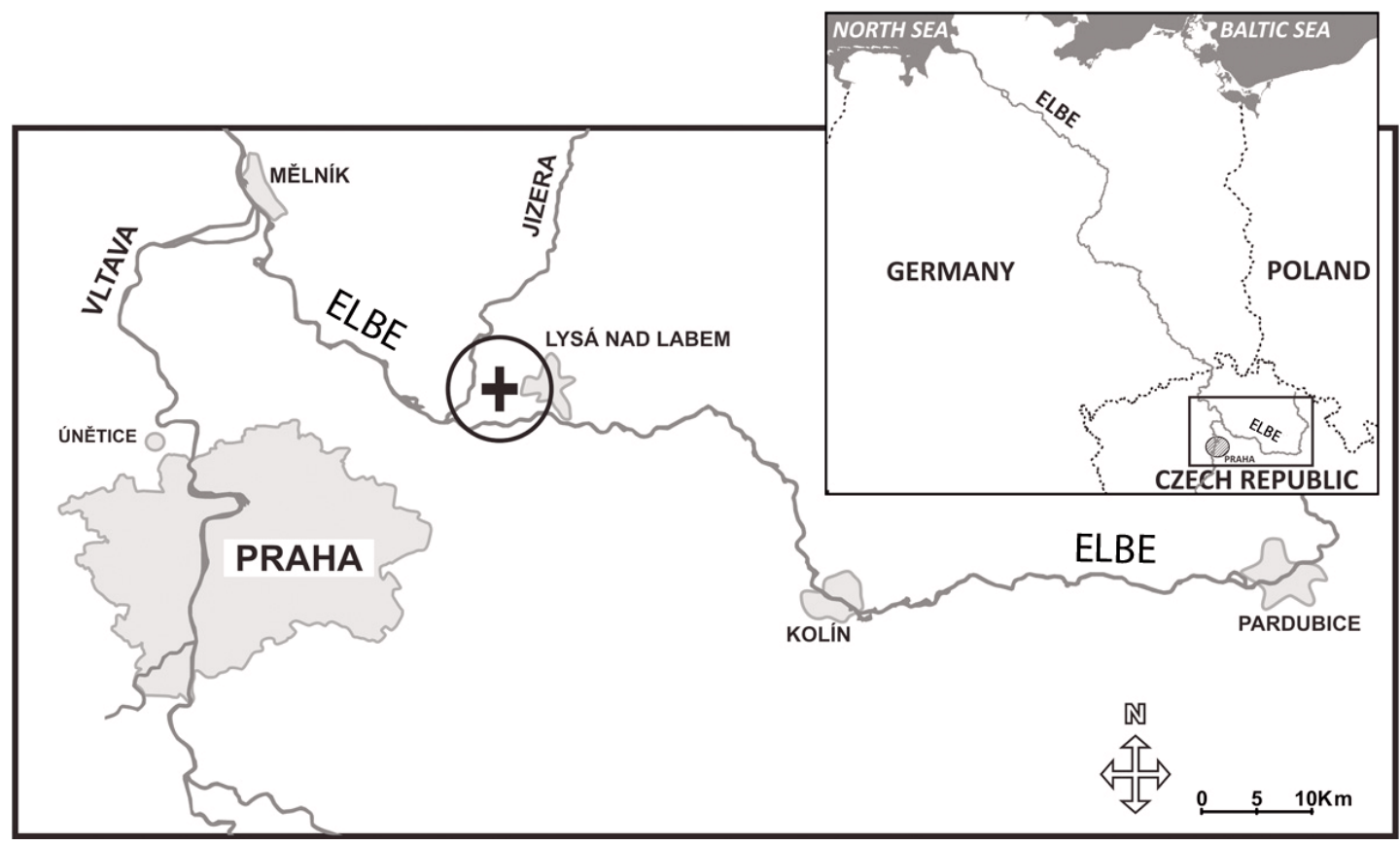

Figure 1

Position of the study site in the European context (black cross in circle).

immersed in the lake. On 10th October 2010 they were equipped with radio transmitters MST930, $4 \mathrm{~g}$ in air, $9.5 \times 26 \mathrm{~mm}$, 24-cm external whip antenna (Lotek Engineering Inc., Newmarket, Ontario, Canada). The radio transmitters were surgically implanted into the peritoneal cavity through a lateral incision situated circa $1 \mathrm{~cm}$ above the pelvic fin. The whip antenna was arranged to exit the body through the incision which was closed by two separate stitches using sterile, braided, absorbable suture (Ethicon Coated Vicryl W9113, Johnson \& Johnson, St. Stevens Woluwe, Belgium). The mass of the transmitter never exceeded $2 \%$ of the fish body mass in air (Winter, 1996). In order to prolong the functioning of the transmitters, which were quite small and had a low battery capacity, they were programmed to only emit a signal one day per week (ON for 1 day/ OFF for 6 days). The programming extended the calculated battery life to 438 days (the original battery life of unprogrammed transmitters is 117 days). After 1st February, however, the transmitters started to work erratically with unpredictable on and off periods because of an error in the programming caused by the manufacturer. The surgery was performed under 2-phenoxy-ethanol $\left(0.2 \mathrm{ml} \cdot \mathrm{L}^{-1}\right)$ anaesthesia. The Animal Use Protocol (No. 6/2010) issued by the Czech University of Life Sciences in Prague was approved by the Ministry of Education, Youth and Sports of the Czech Republic (permit No. 22103/2010-30).

\section{> FISH TRACKING}

The catfish were released on 10th October 2010. The first three weeks of their activity were not analysed due to the possible impact of the implantation on the fish's spatial and temporal activity (Bridger and Booth, 2003). The tracking therefore started on 2nd November. The last data analysed were from 1st February. The fish were tracked on a weekly basis, always for a 24-h period. Fish positions during the 24-h cycle were determined by triangulation at eight subsequent three-hour intervals. A radio receiver SRX 400A/W5XS and a three-element Yagi antenna F 140-3FB (Lotek Engineering Inc., Newmarket, Ontario, Canada) were used for tracking. The accuracy of the fish position determination was estimated to be $\pm 1 \mathrm{~m}$ according to a calibration procedure repeatedly performed with a tag located on the lake bed $(n=100$; mean $=0.74 \mathrm{~m} ; \min =0 \mathrm{~m} ; \max =3.2 \mathrm{~m}$ ). 
A
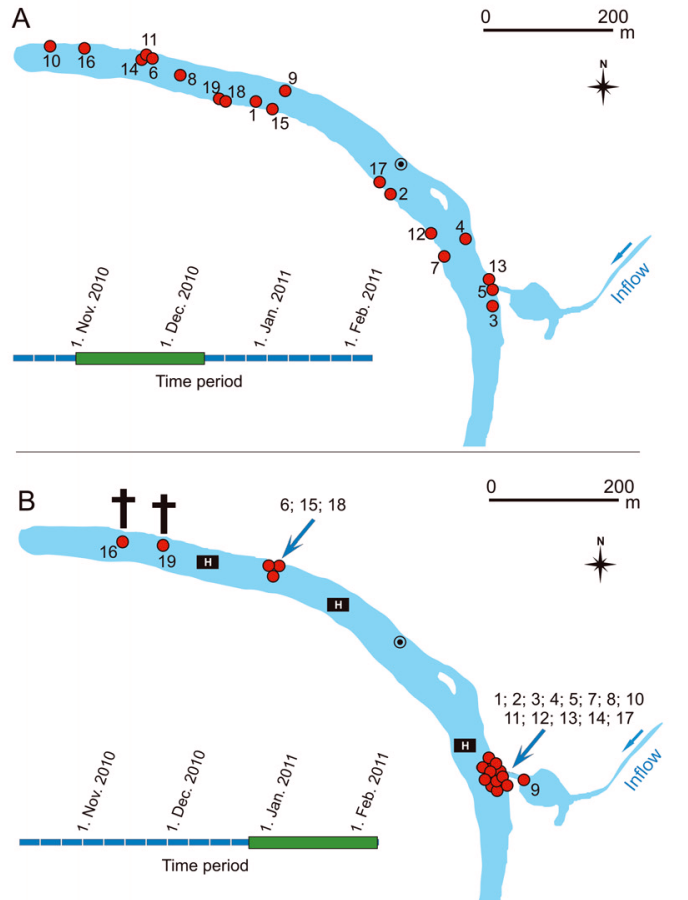

Resting place of fish with the identification

7 number of the individual

H Holes cut in ice by members of local anglers' organizatio
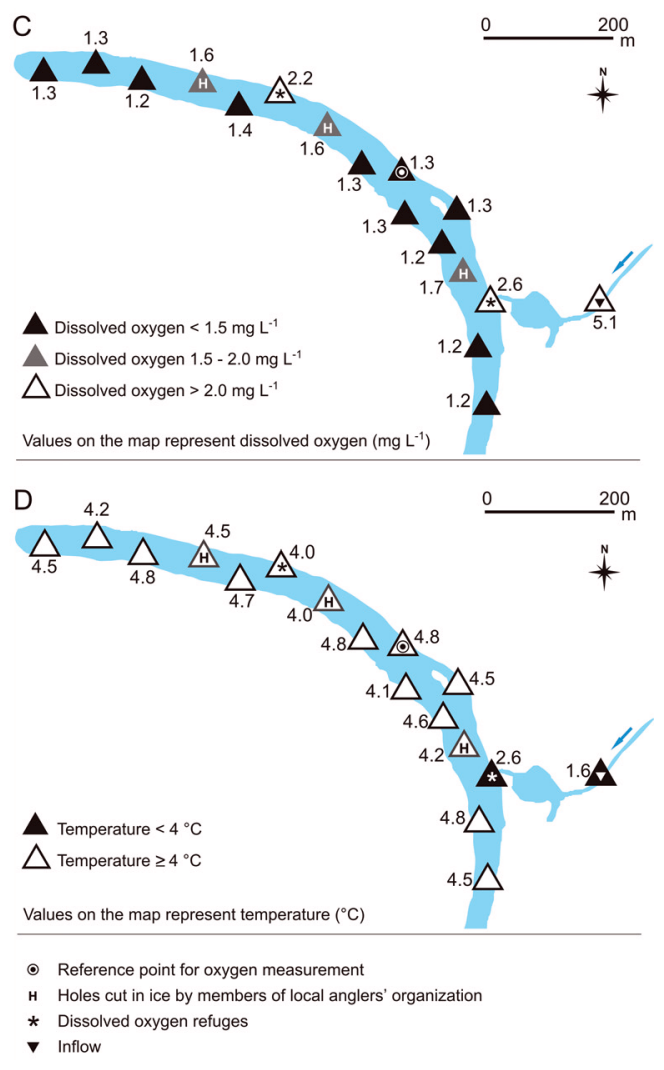

\section{Figure 2}

Map of resting places of juvenile European catfish (Silurus glanis) in Byšická oxbow lake. A - Situation in the period from 2nd November to 14th December 2010 (before oxygen deficiency) B - Situation in the period from 28th December 2010 to 1st February 2011 (after oxygen deficiency).

Within the periods, the change in resting places (relocations) was minimal. All the fish that successfully survived winter were assembled in two small areas with oxygen levels no lower than $2.2 \mathrm{mg} \cdot \mathrm{L}^{-1}$. Two individuals which did not move to these two sites died. The southern part of the oxbow is not depicted because it is shallow, muddy and not inhabited by fish. C - Spatial distribution of DO values on the day when DO minimum values were detected (21st December 2010). D - Spatial distribution of temperatures on the day when DO minimum values were detected (21st December 2010).

\section{$>$ ABIOTIC VARIABLES}

Dissolved oxygen (DO) $\left(\mathrm{mg} \cdot \mathrm{L}^{-1}\right)$ and water temperature $\left({ }^{\circ} \mathrm{C}\right)$ were measured during each tracking day at dawn. Prior to the study, the spatial variability of DO in the lake was repetitively investigated using ten randomly chosen points (three investigations in three different weeks). Because the spatial variability was low and differences in DO at the points were no greater than $0.2 \mathrm{mg} \cdot \mathrm{L}^{-1}$, we decided to use one stable reference point, which was situated in the central part of the lake (see Figure 2), two metres from the bank. As the lake is very shallow, we measured temperature and DO at a single point of the water column. European catfish is a benthic fish, so the values were measured approximately $10 \mathrm{~cm}$ above the bottom using the multimeters Multi 3420 WTW (WTW Wissenschaftlich-Technische Werkstätten GmbH, Weilheim, Germany) and Gryf 464 (GRYF HB, spol. s r.o., Havlickuv Brod, Czech Republic). After the unexpected increase in activity and after the relocation of fish, which was detected during tracking on 21st December 2010, the change in DO level was assumed to be a possible cause. From 21st December 2010, DO levels were also recorded: (1) at the two places where the fish moved to; and (2) near three holes in the ice, which were cut by members of a local anglers' organisation irregularly circa twice a month using a chainsaw (see Figure 2). During the DO deficiency period (21st December 2010), the low spatial variability of DO at other places 
was once more proved using ten randomly chosen points (see Figure 2C). The presence of ice cover and snow was also monitored.

\section{> SURVIVAL DETERMINATION}

A fish was pronounced dead when either its carcass was found or when its transmitter was found on the bank. A fish was considered alive until the last measurable position shift of the individual.

\section{> DATA ANALYSES}

Fish positions were plotted on a map using Quantum GIS (ver. 1.6.0. "Copiapo"); azimuths were plotted with the plugin "Tarsius" (www.tarsiusproject.org/download). "Resting place" was defined as a restricted area of $2 \times 2 \mathrm{~m}$ at maximum where fish spend daytime (at least three subsequent three-hour intervals, of which at least two were during daytime). "Movement" was defined as the sum total of the distance $(\mathrm{m})$ each individual moved during the 24- $\mathrm{h}$ monitoring period. "Relocation" was defined as the distance $(\mathrm{m})$ between the centre of each resting place of each individual between two successive weeks. "Home range" (HR) was determined as a MCP (minimum convex polygon) of the fish position during a 24-h period using the Home Range Analysis plugin for Quantum GIS. The boundary value for DO conditions was used according to Massabuau and Forgue (1995), who state that European catfish can tolerate DO values higher than $1.5 \mathrm{mg} \cdot \mathrm{L}^{-1}$ in the long term, values lower than $1.5 \mathrm{mg} \cdot \mathrm{L}^{-1} \mathrm{be}-$ ing critical. We used this criterion to distinguish between sufficient (higher than $1.5 \mathrm{mg} \cdot \mathrm{L}^{-1}$ ) and deficient (lower than $1.5 \mathrm{mg} \cdot \mathrm{L}^{-1}$ ) DO conditions throughout the study period. Values of individual fish relocation, movement and HR were matched with the DO value at the reference point, except the situation when an individual reached a DO refuge $(10 \mathrm{~m}$ at maximum from the centre of the refuge). DO refuges were defined as two places where the fish moved to on/after 21st December 2010 (see Figure 2B). Levels of DO at these refuges were obviously different from the common conditions represented by the reference point (Figure 2C, Figure 3). If an individual reached a DO refuge area, its relocation, movement and HR value were matched with the DO value measured in the centre of the refuge area.

\section{> STATISTICAL ANALYSES}

The statistical analyses were performed using the SAS software package (SAS Institute Inc., version 9.2, www.sas.com). The data were $\log _{10}$ transformed to meet normality and/or homoscedasticity requirements when needed.

The influence of DO conditions on catfish relocation and movement was analysed using a linear mixed model (LMM) with random factors (PROC MIXED). The random factors were used to account for repeated measurements collected for the same experimental units (individual fish) across the duration of the experiment. The significance of the explanatory variable "DO level" (i.e., a fixed effect) in the particular model was assessed using an F-test. Least-squares means (LSM), henceforth referred to as "adjusted means", were computed for each significant class explanatory variable. Differences between the classes were tested with a $t$-test and a Tukey-Kramer adjustment for multiple comparisons. The degrees of freedom were calculated using the Kenward-Roger method (Kenward and Roger, 1997).

\section{RESULTS}

\section{> FISH TRACKING}

In the period between 2nd November and 14th December 2010, fish had generally stable resting places (Figure 2A) and stable HR of $9 \mathrm{~m}^{2}$ maximum (mean $0.2 \mathrm{~m}^{2}$, S.D. $0.9 \mathrm{~m}^{2}$ ). Within 

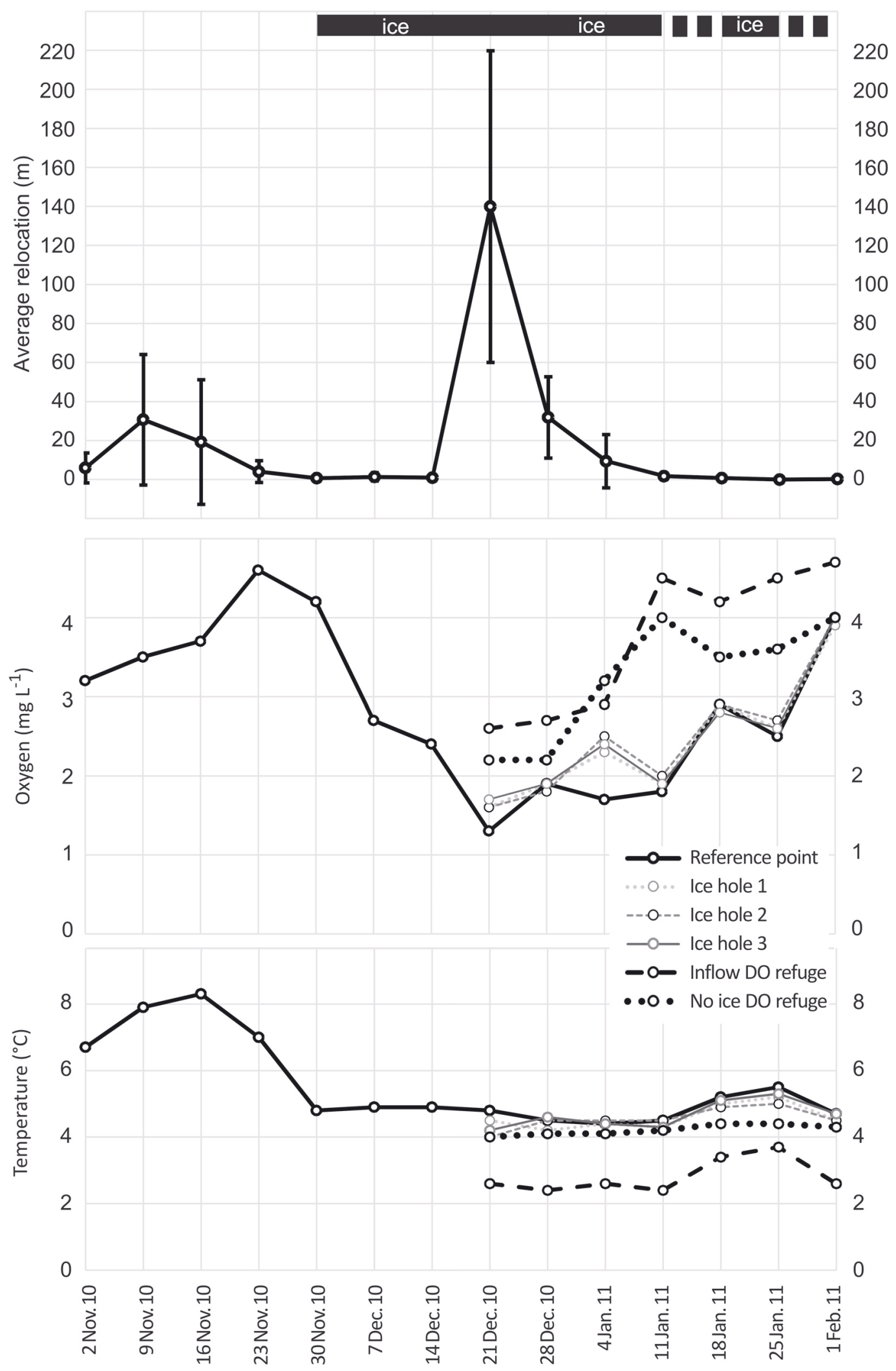

Figure 3

Average relocation of European catfish between two successive weeks and values of water temperature and dissolved oxygen in the period from 2nd November 2010 to 1st February 2011. Value of the relocation is presented as the mean with a confidence interval of all specimens on each day. 
24-h cycles, the movement of fish was usually minimal with a maximum of $18 \mathrm{~m} \cdot$ day $^{-1}$ (mean $0.74 \mathrm{~m} \cdot \mathrm{day}^{-1}$, S.D. $2.09 \mathrm{~m} \cdot \mathrm{day}^{-1}$ ). On $21 \mathrm{st}$ December 2010, large relocation of almost all individuals was detected, and six individuals displayed considerable activity during the 24-h cycle with values of movement up to $259 \mathrm{~m} \cdot$ day $^{-1}$ (mean $35.21 \mathrm{~m} \cdot \mathrm{day}^{-1}$, S.D. 67.26). The extent of average relocation during the whole period from 2nd November 2010 to 1 st February 2011 is shown in Figure 3. Finally, 17 of the fish occupied two very restricted areas (Figure 2B), and only two individuals stayed out of these areas, in places with deficient DO levels. After 4th January, all the relocations and movements ceased again. The values and variability of relocation, movement and HR among individuals are summarised in Table I.

\section{> ENVIRONMENTAL VARIABLES}

The lake was covered with ice from 30th November, and as early as 7th December also with an additional layer of snow at least $5 \mathrm{~cm}$ thick. Ice covered the lake until 1st February, with only partial thawing at the banks during periods from 11th to 18th January and 25th January to 1 st February. The DO and temperature conditions in the lake are shown in Figure 3. The DO minimum occurred on 21st December 2010 with a DO concentration of $1.3 \mathrm{mg} \cdot \mathrm{L}^{-1}$. The values at the holes cut by angler volunteers were slightly higher (the minimum DO was detected on $21 \mathrm{st}$ December 2010 with a DO concentration of $\left.1.6 \mathrm{mg} \cdot \mathrm{L}^{-1}\right)$. At the two places to which the fish moved, the DO concentrations were highest (the minimum DO was detected on $21 \mathrm{st}$ December 2010 with a DO concentration of $2.2 \mathrm{mg} \cdot \mathrm{L}^{-1}$ ). Spatial distribution of DO minimum values is shown in Figure 2C; temperatures during the same period are shown in Figure 2D.

\section{>IMPACT OF DO DEFICIENCY ON EUROPEAN CATFISH BEHAVIOUR}

The extent of relocations, movements and HR is summarised in Table I. The relocation of individuals depended on the DO concentration and was significantly higher when fish were exposed to deficient DO values under $1.5 \mathrm{mg} \cdot \mathrm{L}^{-1}\left(F_{1,199}=74.37, P<0.0001\right.$; Tukey-Kramer Adj. $P<0.0001$; Figure 4A). Movement increased in the deficient DO conditions as well $\left(F_{1,214}=26.48, P<0.0001\right.$; Tukey-Kramer Adj. $P<0.0001$; Figure 4B).

In cases of DO deficiency, the fish left their previous resting places and HR, and simultaneously relocated to two restricted places with the most favourable DO conditions (see Figure $2 \mathrm{~B}$ and Figure $2 \mathrm{C}$ ). This demonstrates that the increase in the movement and relocation was motivated by searching for higher DO levels. When fish reached DO refuges, relocations and movements ceased. The catfish remained at these sites after DO levels had recovered in the whole lake.

The two individuals that stayed in the places with deficient DO levels died. The transmitter of one individual with remains of the fish carcass was picked up by a scuba diver from the lake in the spring. The transmitter (still operating) of the other fish was found on the bank, five metres inland. All the other fish continued to display movements after 1st February and were therefore assumed to have survived.

\section{DISCUSSION}

Although information concerning the behaviour of European catfish in the natural environment is highly limited, this species is assumed to have a physiological optimum of $25-27^{\circ} \mathrm{C}$, when its activity is at its peak (Copp et al., 2009). In cold water during winter time, the activity of European catfish is minimal (Slavík et al., 2007; Copp et al., 2009). However, our telemetry study revealed the possibility of short-term high activity in winter in response to sub-optimal and/or potentially lethal environmental variables.

Based on the measurements of environmental variables, we hypothesised that the initial stimulus, which initiated movement as well as relocation, could have been DO deficiency. Our results support our hypothesis and show that the temporal activity and also spatial distribution 


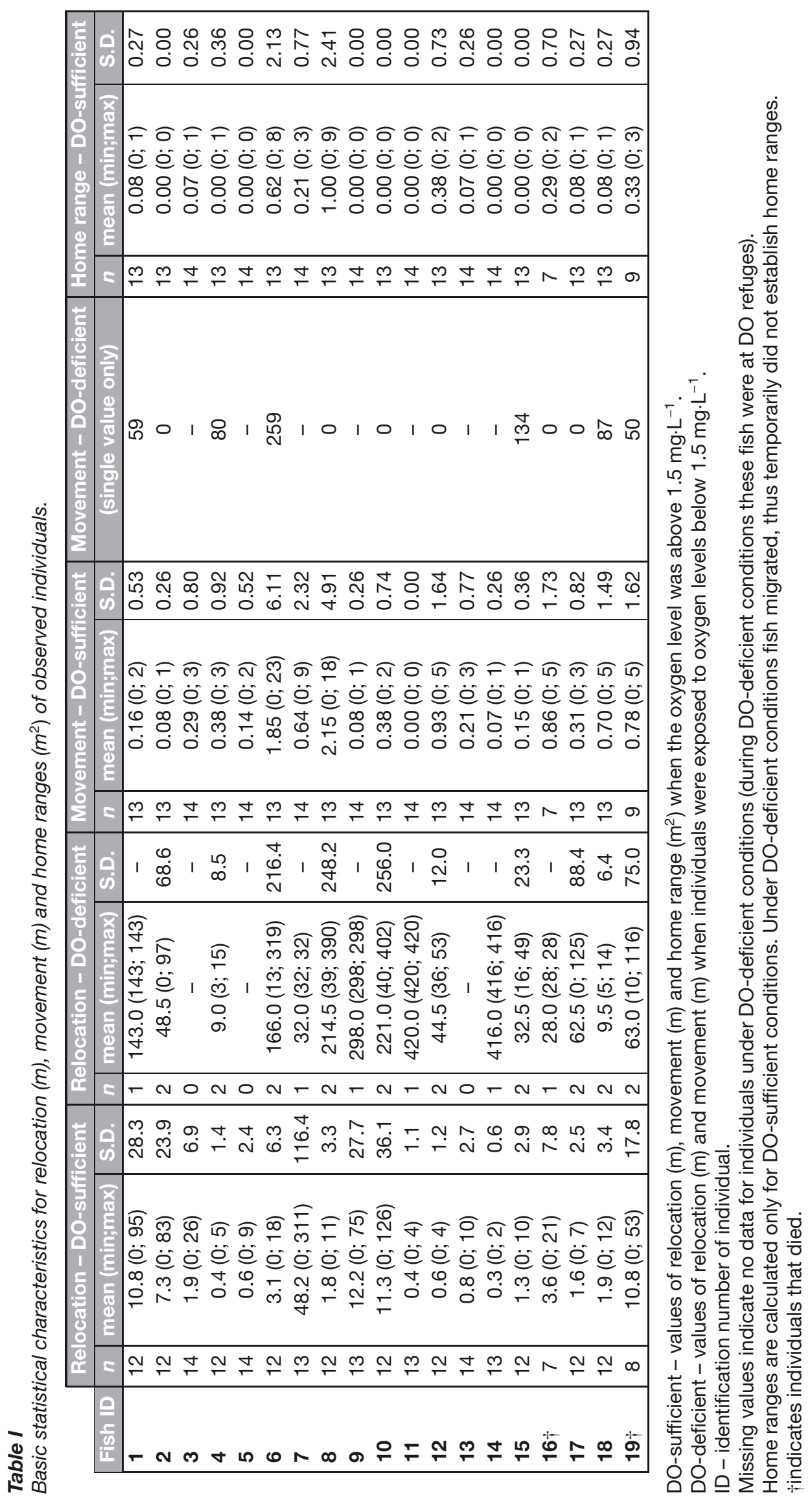




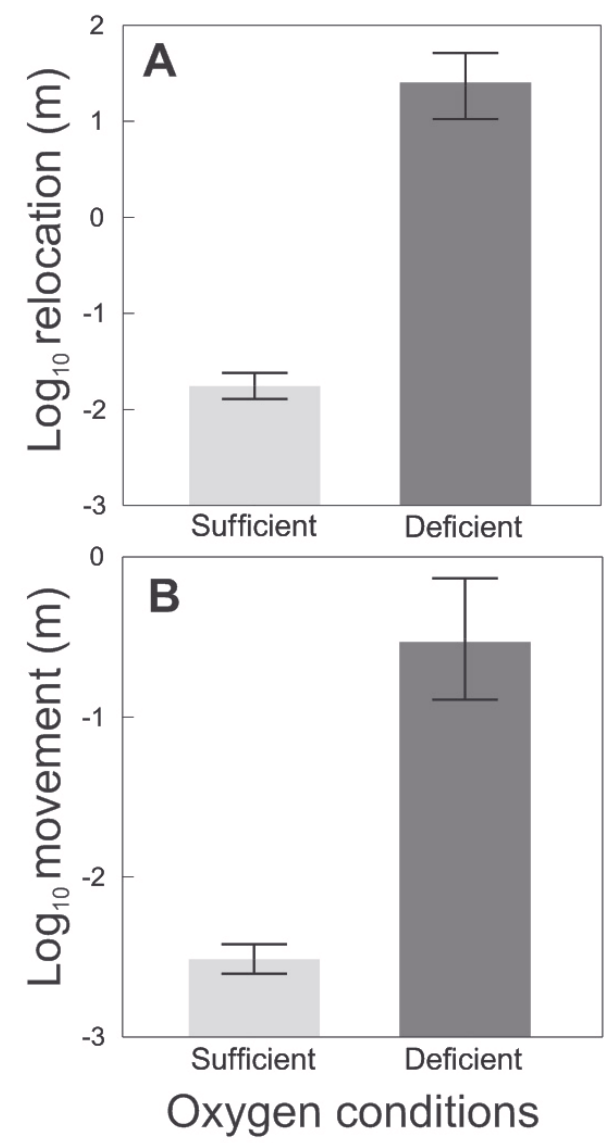

\section{Figure 4}

European catfish relocations $(A)$ and movements $(B)$ under oxygen-deficient and oxygen-sufficient condition. Values are adjusted means \pm S.E. of log10-transformed data. Oxygen deficiency was defined as the situation when fish were exposed to oxygen concentrations lower than $1.5 \mathrm{mg} \cdot \mathrm{L}^{-1}$.

of individuals was affected by low oxygen levels. Despite the fact that relocations in our case were not long-distance, the monitored relocations were synchronised and stretched far beyond the borders of the initial HR of individuals. In a certain way, these relocations can be understood as a "refuge migration" sensu Lucas and Baras (2001). We assume that DO deficiency was caused by the combination of the accumulation of decomposing autumn leaf litter and the presence of a total and permanent ice cover with snow early in the winter. The snow layer restricts photosynthesis below the ice. This mentioned combination of factors is the typical initiator of winterkill in this type of habitat (Fast, 1994; Lucas and Baras, 2001).

Copp et al. (2009) stated that the DO concentration limit for the European catfish is 3-3.5 mg. $\mathrm{L}^{-1}$. However, our data prove that, at least during winter, values of DO of up to $2.4 \mathrm{mg} \cdot \mathrm{L}^{-1}$ were endurable in the long term. Values ranging from 1.3 to $2.4 \mathrm{mg} \cdot \mathrm{L}^{-1}$ initiated the great activity and relocation of fish to areas with favourable DO conditions. Our findings are in agreement with Massabuau and Forgue (1995), who state the ability of European catfish to tolerate DO concentrations of up to $1.5 \mathrm{mg} \cdot \mathrm{L}^{-1}$ in the long term. Values between 1 and $1.5 \mathrm{mg} \cdot \mathrm{L}^{-1}$ are said by these authors to be critical; nevertheless, they point out that catfish can sustain these conditions for $24 \mathrm{~h}$. Fish in our study also survived and exhibited movement under conditions with DO concentrations of $1.3 \mathrm{mg} \cdot \mathrm{L}^{-1}$.

A successive increase in aggregation associated with the relocation of the fish to areas with better DO conditions was also observed. European catfish exhibit site fidelity, and they could also be considered a territorial species, which is associated with their solitary behaviour (Carol et al., 2007; Slavík and Horký, 2009). Nevertheless, some information regarding the aggregation of adult European catfish in a very restricted area does exist. Boulêtreau et al. (2011) 
observed such a phenomenon in the Rhone River, but the cause of their behaviour was unclear, and no juveniles participated. Recently, some temporary catfish aggregations connected to their predatory behaviour have also been observed (Cucherousset et al., 2012).

In our case, the tracked individuals displayed site fidelity at first. Each individual had its stable resting place, and the HR was minimal, which could have been bolstered by the low temperature (Slavík et al., 2007). Later on, a large aggregation of fish in two restricted areas took place. This behaviour was forced by DO conditions in the beginning, but the fish stayed aggregated even after the DO deficiency disappeared and DO rose up to $4.0 \mathrm{mg} \cdot \mathrm{L}^{-1}$.

A large aggregation of fish brings many additional aspects, including the formation of biogeochemical hotspots (places where nutrient release by animals exceeds the need of primary producers) (Boulêtreau et al., 2011) or facilitation of spread of disease (Arneberg et al., 1998; Ogut et al., 2005). We hypothesise that the reason why the fish stayed aggregated and why they did not move back to their previous HR is connected to low temperature, which could inhibit the activity of fish.

Preventive actions taken by members of the local anglers' organisation, including cutting holes in the ice, may not contribute to mitigation of DO deficiency. Ice hole cutting is a common practice of fish stock protection in shallow, ice-covered water bodies (Fast, 1994). However, in our study, not a single monitored individual stayed near the holes. This is most likely related to unstable DO conditions in these places, where DO fluctuates based on ice cutting frequency. Natural tributary inflows appear to provide better DO refuge areas during ice cover periods than man-made ice holes. Although the inflow was cold, it remained without ice cover and well oxygenated. Fourteen tracked individuals stayed near the tributary inflow, and one of them even migrated through the stream connection to a nearby pool. Three other individuals stayed near a naturally unfrozen part of the lake surface where diffusion of oxygen into the water from the air was possible. At these two sites, the DO values were highest during the DO-deficient period. This shows the importance of these types of places for fish survival at similar localities. Where catfish are invasive, such areas of high aggregation could be targeted by population control measures. Considering the potential invasiveness of European catfish in its introduced range, there is a need to accent DO deficits as a possible factor which may induce migration and colonisation of new areas.

\section{ACKNOWLEDGEMENTS}

We thank K. Filinger for field assistance and O. Slavík for his comments on an early version of the manuscript. This study was supported by an S grant from the Ministry of Education, Youth and Sports - Czech Republic, by the grant of the Technology Agency of the Czech Republic No. TD010045 and CIGA No. 20132016.

\section{REFERENCES}

Arneberg P., Skorping A., Grenfell B. and Read A.F., 1998. Host densities as determinants of abundance in parasite communities. Proc. $R$. Soc. B, 265, 1283-1289.

Bauer C. and Schlott G., 2006. Reaction of common carp (Cyprinus carpio, L.) to oxygen deficiency in winter as an example for the suitability of radio telemetry for monitoring the reaction of fish to stress factors in pond aquaculture. Aquac. Res., 37, 248-254.

Bevacqua D., Andrello M., Melia P., Vincenzi S., De Leo G.A. and Crivelli A.J., 2011. Densitydependent and inter-specific interactions affecting European eel settlement in freshwater habitats. Hydrobiologia, 671, 259-265.

Boulêtreau S., Cucherousset J., Villéger S., Masson R. and Santoul F., 2011. Colossal Aggregations of Giant Alien Freshwater Fish as a Potential Biogeochemical Hotspot. PLoS ONE, 6, e25732.

Bridger C.J. and Booth R.K., 2003. The Effects of Biotelemetry Transmitter Presence and Attachment Procedures on Fish Physiology and Behavior. Rev. Fish. Sci., 11, $13-34$. 
Carol J., Zamora L. and García-Berthou E., 2007. Preliminary telemetry data on the patterns and habitat use of European catfish (Silurus glanis) in a reservoir of the River Ebro, Spain. Ecol. Freshw. Fish, 16, 450-456.

Copp G.H., Britton J.R., Cucherousset J., Garcia-Berthou E., Kirk R., Peeler E. and Stakenas S., 2009. Voracious invader or benign feline? A review of the environmental biology of European catfish Silurus glanis in its native and introduced ranges. Fish. Fish., 10, 252-282.

Cucherousset J., Boulêtreau S., Azémar F., Compin A., Guillaume M. and Santoul F., 2012. "Freshwater Killer Whales": Beaching Behavior of an Alien Fish to Hunt Land Birds. PLoS ONE, 7, e50840.

Danylchuk A.J. and Tonn, W.M., 2006. Natural disturbace and life history: consequences of winterkill on fathead minnow in boreal lakes. J. Fish Biol., 68, 681-694.

Dekar M.P., Magoulick D.D. and Beringer J., 2010. Bioenergetics assessment of fish and crayfish consumption by river otter (Lontra canadensis): integrating prey availability, diet, and field metabolic rate. Can. J. Fish. Aquat. Sci., 67, 1439-1448.

Ellis C.R. and Stefan H.G., 1989. Oxygen demand in ice covered lakes as it pertains to winter aeration. J. Am. Water Resour. Assoc., 25, 1169-1176.

Fast A.W., 1994. Winterkill prevention in lakes and ponds using artificial aeration. Rev. Fish. Sci., 2, 23-77.

Kenward M.G. and Roger J.H., 1997. Small sample inference for fixed effects from restricted maximum likelihood. Biometrics, 53, 983-997.

Lelek A., Libosvárský J., Peòáz M., Bezdik R. and Macháèek Z., 1964. Observation on fish under ice in winter. Ekologia Polska (Seria A), 12, 305-312.

Lucas C.M. and Baras E., 2001. Migration of Freshwater Fishes, Blackwell Science, Oxford, 440 p.

Martino A., Sylväranta J., Crivelli A., Cereghino R. and Santoul F., 2011. Is European catfish a threat to eels in southern France? Aquat. Conserv.-Mar. Freshw. Ecosyst., 21, 276-281.

Massabuau J.C. and Forgue J., 1995. Les capacités d'adaptation du silure glane en hypoxie : un cas exemplaire d'homéostasie du milieu intérieur (How sheatfish, Silurus glanis, maintains oxygen supply in hypoxia: a key example of oxygen homeostasis). Aquat. Living Resour., 8, 423-430.

Ogut H., LaPatra S.E. and Reno P.W., 2005. Effects of host density on furunculosis epidemics determined by the simple SIR model. Prev. Vet. Med., 71(1-2), 83-90.

Slavík O. and Horký P., 2009. When fish meet fish as determined by physiological senzors. Ecol. Freshw. Fish., 18, 501-506.

Slavík O., Horký P., Bartoš L., Koláøová J. and Randák T., 2007. Diurnal and seasonal behaviour of adult and juvenile European catfish as determined by radio-telemetry in the River Berounka, Czech Republic. J. Fish Biol., 71, 101-114.

Stewart D.C., Middlemas S.J., Gardiner W.R., Mackay S. and Armstrong J.D., 2005. Diet and prey selection of cormorants (Phalacrocorax carbo) at Loch Leven, a major stocked trout fishery. J. Zool., 267, 191-201.

Ultsch G.R., 1989. Ecology and physiology of hibernation and overwintering among freshwater fishes, turtles and snakes. Biol. Rev., 64, 435-516.

Winter J.D., 1996. Advances in underwater biotelemetry. In: Murphy B.R., Willis D.W. (ed.), Fisheries Techniques, 2nd Edition. American Fisheries Society, Bethesda, 555-590. 